\title{
THE U.K. ATOMIC ENERGY AUTHORITY
}

$\mathrm{T}$ HE accounts of the Atomic Energy Authority for the year ended March 31, 1962*, were issued last April, together with the report of the Comptroller and Auditor-General, Sir Edmund Compton. They are now included in the ninth annual report of the Authority for the year 1962-63 $\dagger$, which adds a further appendix comparing the 1962-63 grants and the 1963-64 estimates, which stand at $£ 108,124,000$ and $£ 114,897,000$ gross receipts - the latter bringing the net expenditure to $£ 67,876,000$ and $£ 60,204,000$, respectively. Of the gross total, salaries, etc., account for $£ 43,185,000$ and $£ 42,198,000$, respectively; research, development and design contracts with industry, universities, etc., for $£ 4,881,000$ and $£ 4,612,000$; contributions towards the International Atomic Energy Projects Dragon and Halden for $£ 2,329,000$ and $£ 2,195,000$; and grants to the National Institute for Research in Nuclear Science for $£ 7,205,000$ and $£ 8,445,000$, respectively.

While the form of the balance sheet for 1961-62 is substantially changed from previous presentations, as a result of some change in security requirements, and the published information has been expanded, the operating account is still withheld from publication on security grounds. General research in the year ended March 31, 1962 , is put at $£ 40,557,186$, weapons research, excluding military contracts, at $£ 8,263,215$, and grants to the National Institute for Research in Nuclear Science at

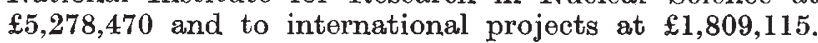
Moreover, in the Consolidated Civil Trading Account, which shows a net profit of $£ 24,080$, contributions to research and development appear at $£ 591,423$, compared with

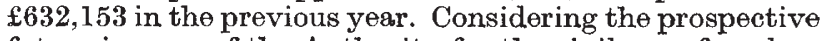
future income of the Authority for the civil use of nuclear energy, Sir Edmund notes that in 1957 the Authority concluded that the possibilities of the magnox reactor system, derived from the Calder Hall reactor, would be largely exhausted in the first stage of the nuclear power programme. Further development of the advanced gascooled reactor would permit higher operating temperatures and fuel ratings with consequent greater efficiency. The construction of such a prototype was approved in December 1957, and, when completed in 1962, this had cost about $£ 9.7$ million, while some $£ 10$ million capital and current expenditure had been incurred in the development and production of beryllium for canning the fuel elements-a method of canning later found to be unsatisfactory and abandoned in favour of stainless steel. Further expenditure will be incurred in developing the system to full commercial use, and Sir Edmund adds that the Electricity Boards are not committed to the adoption of this system and that the Authority's own view is that the adoption of a particular system by the Generating Boards in the United Kingdom or overseas should await the demonstration of its feasibility, safety and economics.

Expenditure on the development of magnox fuel elements for civil use is charged partly to the Exchequer as non-trading expenditure and partly to trading, and an item of $£ 14,047,382$ for major development projects, charged to the Exchequer, includes some expenditure on research and development in support of the nuclear power programme. 'Genetic' development, in which the basic

* Atomic Energy Authority Act, 1954. Accounts 1961-62: Balance Sheet of The United Kingdom Atomic Energy Authority as at 31 March, 1962, and Accounts for the year ended 31 March, 1962; together with the

Report of the Comptroller and Auditor-General thereon. (House of Commons
Paper No. 187.) Pp. 14. ((Tondon: H.M.S.O., 1963.) 1s. $6 d$. net.
† United Kingdom Atomic Energy Authority. Ninth Annual Report for † United Kingdom Atomic Energy Authority. Ninth Annual Report for H.M.S.O., 1963.) 68. 6d. net. (See also p. 1121 of this issue of Nature.) designs of the reactor and its fuel are established, and the feasibility, reliability and economics of the system are demonstrated, is regarded by the Authority as forming part of its statutory obligation to undertake civil research and development. After commercial exploitation begins, the cost of development is regarded as part of the cost of production and charged in the Trading Account. As from April 1, 1962, expenditure on further development of magnox fuel elements became regarded as appropriate to the commercial exploitation phase and sales prices scheduled for the following five years.

In the Authority's annual report the percentage deployment of effort between reactor projects in terms of qualified scientists and engineers, excluding basic research, is now given as follows: advanced gas-cooled reactor, 23 ; steam-generating heavy water reactor, 15; fast reactor, 36 ; civil marine-propulsion reactor, 13 ; and hightemperature gas-cooled reactor, 13. Generation of electricity from the magnox reactors at Calder Hall and Chapelcross increased by 13 per cent, and the reactors of the Central Electricity Generating Board at Bradwell and Berkeley have started delivering to the grid, as did the advanced gas-cooled reactor at Windscale in February, while by March 31 the Dounreay fast reactor had generated. 2.5 million $\mathrm{kWh}$, of which 10 per cent had been exported to the grid. Nor was progress confined to the reactor field. During the year, the world's first two cobalt-60 industrial irradiation plants, designed specifically for sterilization of medical products, began continuous operation, one at Slough and the other at Edinburgh. Both were built under licence from the Authority following large-scale experiments at the Wantage Research Laboratory. On the other hand, with the meeting of the Government's requirements for enriched uranium for defence, it was decided to reduce the output of the diffusion plant at Capenhurst to the minimum level necessary to keep the plant in product; a substantial reduction of manpower at the factory had to be effected by the end of 1962. About 50 per cent of the redundant employees have found alternative employment inside or outside the Authority.

Of the expenditure in 1962-63 on the Authority's programme of civil research and development of $\mathfrak{\& 4 8}$ million, some £35 million was current expenditure and $£ 13$ million capital facilities. Of 2,825 graduates or professional scientists or engineers employed on the programme at March 31, 200 were working for other bodies on repayment; 1,880 were engaged on the reactor development programme and the reactor systems research, 470 on general research, 190 on plasma physics and fusion research, and 85 on isotopes research. Some account of the research on reactor systems, which includes nuclear data for reactor calculations, experimental measurements in reactor physics and heat transfer in reactors, as well as instrumentation, fuel materials, canning and structural materials, and moderators and coolants, is given in a separate chapter in the report.

The ninth report also includes chapters on general research, on plasma physics and fusion research, on nuclear weapons and test direction, on commercial operations and raw materials, on health and safety, on information services, and on the A.uthority's international relations and on staff. Reductions in manpower raised considerable problems and recruitment was on a much lower scale, but the lower number of graduate scientific and engineering recruits was broadly sufficient for the reduced need; in 1963 the reduction will be mainly on the engineering side but some scientific entrants will be required. Critical 
appraisal of training methods continued, and the variety and scope of internal training was wide, with special emphasis on the training of industrial supervisors. At the Harwell Reactor School, which was attended by 522 students, of whom 26 were from overseas and 262 were Authority staff, two new courses for Authority staff were an extension course in reactor engineering and a course on applied mathematies for engineers; a course for university engineering staff and one for science masters were also held. At the Calder Operations School, where 711 people (213 from overseas) have now attended, standard courses were held for physicists and engineers, and a new course for lecturers at universities and technical colleges.

Some research is included in the Authority's health and safety programme, for example, measurements of radioactivity in air and in rain-water, the study of radiological protection, including the development of instruments for precise measurements of radiation dose-rates down to very low levels and the determination of plutonium in urine and in the body. There was a marked increase in the Authority's commercial activities. Sales of radioisotopes rose from $£ 1.4$ million in $1961-62$ to $£ 1.473$ million, of graphito from $£ 2.843$ million to $£ 3$ million, and of reactor fuel from $£ 9.6$ million to $£ 22.5$ million. This year the chapter on general research discusses the programme as a whole, which, on the basic side, aims to supply fundamental scientific knowledge for future developments of nuclear energy, and also to supply the scientific understanding needed to solve problems arising during the rapid development of the present programme. Much of the general applied research programme is concerned with the interactions of neutrons and other radiations with matter on both the nuclear and atomic scale.

In nuclear chemistry, work continued on the determination, by both radiochemical and mass spectrometric methods, of the proportions of fission product atoms formed with various mass numbers in fission by lowenergy neutrons. In theoretical physics, special attention was directed to investigations of the magnetic and electronic properties of transition metals and their alloys, the properties of defects and defect clusters in metals, and the scattering of neutron beams by liquids and solids. In the physics of the solid-state, the individual atomic contributions to the magnetization of ferromagnetic alloys were identified by neutron diffraction techniques, and the weak magnetic properties of vanadium-chromium alloys, in conjunction with other physical measurements, have established the validity of the band models of electronic structure of these alloys. Other research on radiation damage is now concentrated on elucidating the underlying atomic mechanisms, and at the Atomic Weapons Research Establishment the electrical properties of semiconductors are being exploited to provide a sensitive method for analysing mechanisms of radiation damage. A new variable energy cyclotron is being built at Harwell for general studies on the physical and chemical effects of radiation. Research continues on the physical metallurgy of uranium, plutonium and other metals of technical interest as well as on the physical and chemical properties of the oxides, carbides, nitrides and sulphides of fissile and fertile elements. Besides chemical engineering research in the role of bubbles in gas and solid movement, an extensive programme of research is being undertaken in electronics.

The Culham Laboratory programme remains concerned with stability studies on a wide range of plasma containment systems, including both pinch configurations and magnetic traps. Zeta remains the main toroidal pinch experiment, and has been modified to increase both the initial rate of rise of current in the discharge and the time during which the current is held constant after the initial rise. Besides the study of several linear pinch systems, three methods of injecting particles into a magnetic mirror trap are being studied. Effort has been devoted to the production of computer programmes for magnetohydrodynamic and electromagnetic problems, and a long-term programme of technological studies to support the laboratory's scientific programme has been established.

\section{BIOLOGY OF RADIOIODINE}

$\mathrm{T}$ HE Hanford symposium on"The Biology of Radioiodine" was held in Richland, Washington, during July 17-19, under the joint sponsorship of the U.S. Atomic Energy Commission and the Hanford Laboratories of the General Electric Co. (contract No. $A T(45-1)-1350$ between the Atomic Energy Commission and the General Electric Co.). About 150 visiting scientists from Belgium, Canada, France, India, Japan, United Arab Republic, United Kingdom, West Germany and the United States joined more than 70 scientists of Hanford Laboratories for two and a half days of formal presentations and a tour of the facilities of the Laboratories.

Participants were welcomed to the sessions of the first day by Dr. H. A. Kornberg, manager of the Biology Laboratory of Hanford Laboratories. He noted that this symposium on radioiodine was the second in an annual series, the first having been held in May 1962, on the "Biology of the Transuranium Elements", under the general chairmanship of Dr. R. C. Thompson. The third symposium, to be held in the spring of 1964 , will be concerned with the "Biology of Radioactive Particles and Gases" and will be under the general chairmanship of Dr. W. J. Bair.

The symposium was devoted to evaluating the nature, effects and control of radioiodine in the biosphere under the following four general categories:

(1) "Physical Origin and Dispersion of Radioiodine", which covered sources of environmental radioiodine in nuclear industrial operations, accidents and weapons tests, and the nature and form of iodine dispersed and potentially available to the biota.

(2) "Biological Disposition of Radioiodine", which concerned entry of iodine-131 into and passage through biological systems and included uptake of different radioisotopes of iodine by means of various routes of entry in several species of animals, including those in an aquatic environment.

(3) "Biological Effects of Radioiodine", which emphasized comparativo early and late effects of single and prolonged exposure in young and adults of various species and included carcinogenic effects on the thyroid of iodine and $\mathrm{X}$-irradiation.

(4) "Prophylactic and Therapeutic Measures for Radioiodine", covering protective measures to reduce the thyroid uptake of radioiodine or its effects on the thyroid.

Principal fields within these genoral categories were reviewed by authorities and each review paper was followed by brief reports of unpublished work from many laboratories. Only a few of the fifty papers are here summarized.

The session chairmen were Drs. S. A. Lough and H. D. Bruner of the U.S. Atomic Energy Commission, Dr. A. H. Wolff of the U.S. Public Health Service, Dr. B. M. Dobyns of the Cleveland Metropolitan General Hospital, Dr. E. E. Pochin of the University College Hospital Medical School, London, Dr. Stuart Lindsay of the San Francisco Medical 